10

\title{
Фотоотверждаемая полимерная композиция на основе термостойкого ароматического полиамида для формирования оптических элементов методом двухфотонной полимеризации
}

\author{
(C) Д.В. Ганин ${ }^{1}$, Д.С. Дудова ${ }^{2}$, Б.С. Шавкута ${ }^{2,4}$, O.С. Коркунова $^{3}$, Б.Ч. Холхоев ${ }^{3}$, \\ П.С. Тимашев ${ }^{2,4,5,6}$, В.Ф. Бурдуковский ${ }^{3}$, Н.В. Минаев ${ }^{2}$ \\ ${ }^{1}$ Центр фризического приборостроения Института общей фризики им. А.М. Прохорова РАН, \\ 108840 Троицк, Россия \\ ${ }^{2}$ Институт фотонных технологий Федерального научно-исследовательского центра „Кристаллография и фротоника“ РАН, \\ 108840 Троицк, Россия \\ ${ }^{3}$ Байкальский институт природопользования Сибирского отделения РАН, \\ 670047 Улан-Удэ, Россия \\ ${ }^{4}$ Институт регенеративной медицины Первого МГМУ им. И.М. Сеченова Минздрава России (Сеченовский университет), \\ 119991 Москва, Россия \\ ${ }^{5}$ Институт химической фризики им. Н.Н. Семенова РАН, \\ 119991 Москва, Россия \\ ${ }^{6}$ Химический фракультет МГУ имени М.В. Ломоносова, \\ 119991 Москва, Россия \\ e-mail: ganin@optosystems.ru
}

Поступила в редакцию 11.12.2019 г.

В окончательной редакции 08.03.2020 г.

Принята к публикации 28.03.2020 г.

Установлены оптические свойства полимерной композиции на основе термостойкого ароматического полиамида и разработан подход к формированию трехмерных микрооптических структур методом двухфотонной полимеризации на ее основе. Отработаны режимы формирования прототипов полимерных микрооптических элементов с использованием системы двухфотонной полимеризации с использованием лазерного источника с длиной волны $525 \mathrm{~nm}$. Сформированные структуры соответствовали исходной трехмерной модели, были оптически прозрачны в диапазоне от $450 \mathrm{~nm}$, сохраняли оптическую прозрачность после серии циклов нагрева до $300^{\circ} \mathrm{C}$.

Ключевые слова: фемтосекундное лазерное излучение, многофотонное поглощение, двухфотонная полимеризация, 3D-печать, фотоотверждаемые полимерные композиции, термостойкие ароматические полиамиды.

DOI: $10.21883 /$ OS.2020.07.49560.106-20

\section{Введение}

Разработка новых оптических приборов, появление мощных лазерных источников требуют создания сложных оптических систем с асферическими поверхностями, которые затруднительно произвести традиционными способами. Например, коллимация и фокусировка мощных лазеров и лазерных диодов со сложным модовым составом требует применения дорогих пространственных модуляторов света [1] и сложных оптических систем [2,3]. Решением такой задачи может стать создание асферических оптических элементов, в том числе микронного масштаба [4] по специально рассчитанной компьютерной модели $[5,6]$.

В настоящее время одними из новых перспективных методов создания оптических элементов являются аддитивные технологии, использующие различные прозрачные фотоотверждаемые полимерные композиции (ФПК) и работающие по принципу лазерного или проекционного [7,8] фотоотверждения полимерных материалов. Такие методы основаны на прямом однофотонном се- лективном фотоотверждении тонких слоев полимерных композиций, благодаря чему (по исходной компьютерной модели) послойно формируются структуры размерами до нескольких сантиметров. Недостатком такого подхода при формировании оптических элементов является необходимость дополнительной обработки их поверхности до оптического качества.

Значительного повышения качества формируемых оптических элементов можно добиться, используя метод двухфотонной полимеризации (2ФП), в настоящий момент представленный в виде технологии двухфотонной микростереолитографии [9]. В качестве „чернил“ здесь также могут использоваться различные прозрачные ФПК $[4,10,11]$, в том числе гибридные [12] и наполненные частицами оптических материалов [13]. Фотоотвеждение полимерных композиций происходит за счет одновременного поглощения двух фотонов при облучении сфокусированными ультракороткими импульсами. Область воздействия излучения ограничена геометрическими размерами лазерной перетяжки, что позволяет проводить фотоотверждение в толще полимерной 
композиции без отвеждения поверхности и других областей, по которым распространялось излучение. Возможности современных фемтосекундных лазеров и фокусирующих систем позволяют достигать субмикронного разрешения 2ФП и формировать объекты по сложным компьютерным моделям и развитой топологией поверхности.

Стоит также отметить и другие значительные преимущества метода 2ФП по сравнению с классическими однофотонными методами формирования трехмерных структур методом полимеризации $[14,15]$. Основное преимущество (помимо высокого разрешения и возможности формировать произвольную геометрию) - возможность работы с нестандартными материалами, обладающими, например, высокой вязкостью, не позволяющей формировать тонкие слои при классических методах трехмерной печати. Благодаря непрерывно растущей производительности метода 2ФП $[16,17]$ появляется возможность обойти основное ограничение метода (малые размеры формируемых структур) и формировать все более крупные структуры [18], достигая сантиметрового масштаба при сохранении микронного и субмикронного пространственного разрешения.

В настоящее время актуальной задачей для метода двухфотонной полимеризации является создание полимерных фотоотверждаемых материалов с улучшенными свойствами, а также формирование на их основе 3D-объектов с высоким пространственным разрешением [19]. Традиционными материалами для 2ФП являются различные полимерные (SU-8) [20] и полимеркомпозитные материалы (ORMOCER) [21-23], например на основе циркония, обладающие малой усадкой и выдерживающие нагрев до $200^{\circ} \mathrm{C}$ [24], позволяющие с высокой точностью создавать микроустройства [25]. Новым направлением в этой области является разработка и применение новых термостабильных фотоотверждаемых материалов, сохраняющих свои оптические и механические свойства при температурах до $300^{\circ} \mathrm{C}$ и более (полиэфиры с жесткой цепью и другие) [14,26-28]. Структурирование таких материалов методом 2ФП может стать новым технологическим решением, удешевляющим разработку и создание оптических элементов сложной структуры [29].

Целью представляемой работы являлось определение оптических свойств оригинальной фотоотверждаемой композиции на основе термостойкого ароматического полиамида [20], а также сформированных образцов оптически прозрачных термостойких микрооптических элементов с высоким пространственным разрешением. Для изготовления образцов использовался метод двухфотонной полимеризации [30], который в перспективе позволяет формировать объекты сантиметрового масштаба с микронным и субмикронным разрешением [18] согласно заданной компьютерной модели.

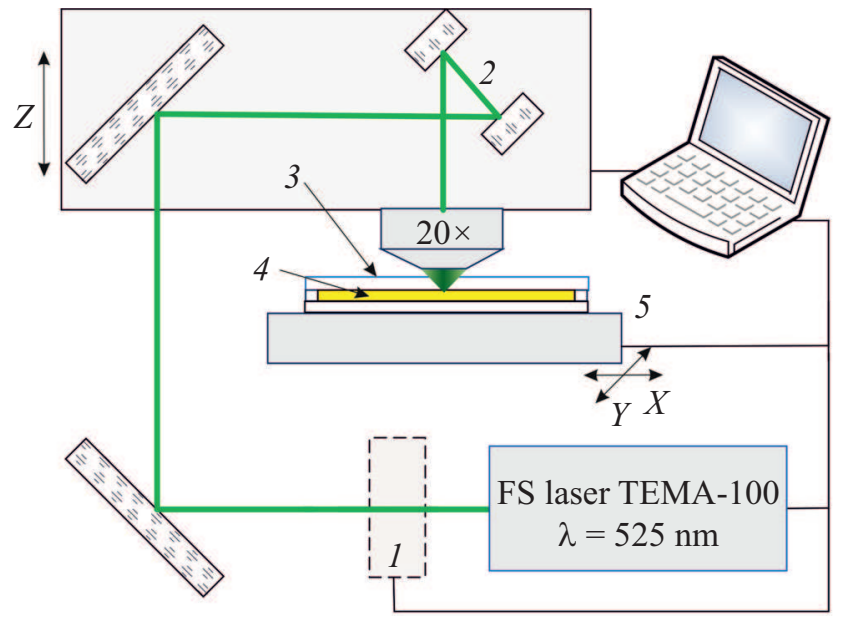

Рис. 1. Схема экспериментальной установки: 1 - аттенюатор, 2 - двухзеркальный гальваносканер, 3 - покровное стекло с силиконовым разделителем, 4 - ФПК, 5 - высокоточный моторизированный транслятор.

\section{Используемые материалы}

В работе использовалась оригинальная ФПК, основу которой составляют термостойкий гетероцепной полимер поли-N,N'-(м-фенилен)изофталамид и диакридамиданилинфталеин, выполняющий роль дифункционального сшивающего агента. Ранее нами было показано [14], что такая композиция может быть успешно использована для формирования термостойких (до $350^{\circ} \mathrm{C}$ ) трехмерных объектов методом классической лазерной стереолитографии. В качестве активного растворителя использовался $\mathrm{N}, \mathrm{N}$-диметилакриламид, который также принимал участие в процессе полимеризации. В качестве фотоинициатора использовался Irgacure 819.

В научных источниках встречаются публикации $[15,31]$ по использованию термостабильных фотоотверждаемых композиций для трехмерной печати методами лазерной стереолитографии или проекционной печати, но не обнаружено публикаций по формированию трехмерных структур методом двухфотонной полимеризации.

\section{Установка двухфотонной полимеризации}

Для формирования трехмерных структур использовалась система двухфотонной лазерной микростереолитографии (рис. 1) [32,33]. В системе использовалось излучение фемтосекундного высокочастотного иттербиевого лазера (ТЕМА-100, Авеста-Проект) с генератором второй гармоники (длина волны $525 \mathrm{~nm}$, длительность импульсов $200 \mathrm{fs}$, частота повторения импульсов $70 \mathrm{MHz}$, средняя мощность до $2 \mathrm{~W})$. Для формирования структуры по трехмерной модели использовалась 
система M3DS (LasernanoFAB, Германия), которая объединяет три моторизированных транслятора на воздушных подшипниках ABL1000 (Aerotech) и высокоскоростной двухкоординатный гальваносканер HuryScan 14 (ScanLab). Система позволяет обрабатывать объем образца ФПК как с помощью перемещения лазерного луча гальваносканером в рабочем поле микрообъектива на скоростях до $50 \mathrm{~mm} / \mathrm{s}$, так и с помощью непосредственного перемещения образца в трехмерном пространстве относительно точки фокусировки луча лазера трехмерным транслятором.

Программно-аппаратное обеспечение позволяет на основе трехмерной модели подготовить управляющую программу, с помощью которой осуществляется процесс послойного отверждение объема ФПК при перемещении лазерного луча в пространстве. Излучение фокусируется с помощью планарных микроскопических объективов с числовыми апертурами вплоть до 0.9, что позволяет формировать фокальную перетяжку диаметром от долей микрометра до нескольких микрометров, внутри которой протекает процесс фотоотверждения ФПК. В экспериментах использовался планарный микроскопический объектив Zeiss EC EPIPLAN 20X с числовой апертурой 0.4 и рабочем полем $200 \times 200 \mu \mathrm{m}$. Формирование крупных объектов, выходящих за рабочее поле микрообъектива, производилось по частям. С помощью гальваносканера осуществлялась быстрое заполнение (в плоскости XY) отдельных слоев области образца, попадающей в рабочее поле объектива, со смещением по оси $Z$. Затем в рабочее поле объектива с помощью линейных трансляторов перемещалась соседняя необработанная область ФПК для формирования следующей части модели. Такой алгоритм позволяет формировать

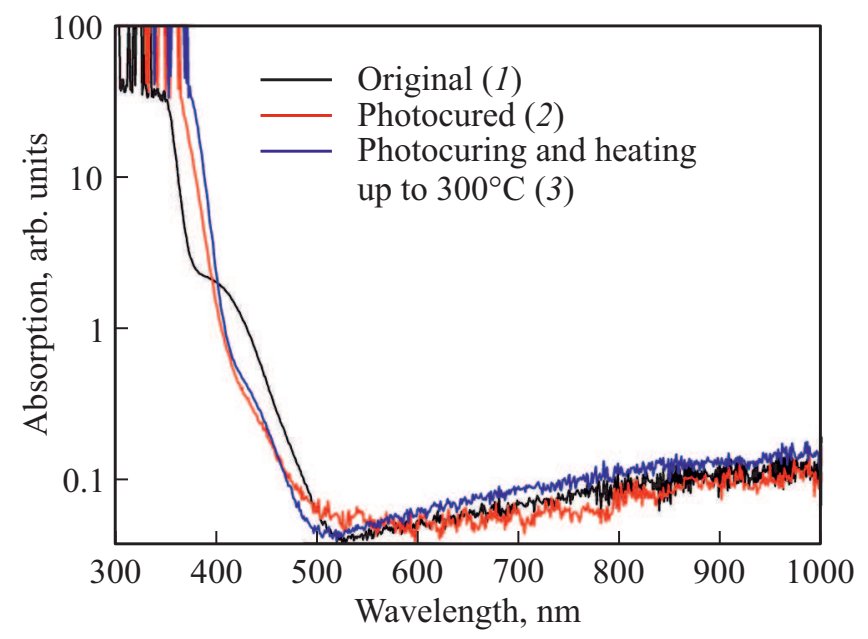

Рис. 2. Спектры поглощения образцов фотоотверждаемой полимерной композиции толщиной $100 \mu \mathrm{m}: 1-$ исходный спектр образца до фотоотверждения; 2 - после фотоотверждения с помощью матрицы светодиодов с длиной волны $365 \mathrm{~nm} ; 3-$ после фотоотверждения и воздействия высокой температуры $\left(300^{\circ} \mathrm{C}\right.$ в течение $\left.1 \mathrm{~h}\right)$. объекты размером до нескольких миллиметров с микронным разрешением.

Для формирования стабильных слоев из ФПК толщиной $1 \mathrm{~mm}$ использовались силиконовые ограничители спейсеры в виде шайб с внутренним диаметром $7 \mathrm{~mm}$, зажатые между двумя покровными стеклами, через которые заводилось лазерное излучение.

Образцы после изготовления исследовались с помощью оптического 3D-микроскопа Huvitz HRM300BDRT-3D в отраженном свете и на просвет, а также с помощью электронного микроскопа PhenomPro-X. Измерение спектров поглощения осуществлялось на спектрофотометре Cary 50. Нагрев образцов осуществлялся в термокамере, оснащенной нагревательным элементом, подключенным к ПИД-терморегулятору. Для дополнительного облучения образцов использовалась матрица УФ светодиодов с длиной волны $365 \mathrm{~nm}$ и мощностью 100 W (Chanzon, Китай).

\section{Экспериментальные результаты}

\section{Исследование оптических свойств фотоотверждаемой композиции}

Для определения оптических свойств, таких как показатель преломления и спектр поглощения исходной и фотоотвержденной ФПК, необходимо было изготовить образцы в виде тонких пленок толщиной $100 \mu \mathrm{m}$ и площадью от $10 \mathrm{~mm}^{2}$. Формирование таких пленок с помощью системы двухфотонной микростереолитографии занимает несколько часов. Поэтому для ускорения формирования образцов часть пленок изготавливались с помощью матрицы светодиодов с длиной волны $365 \mathrm{~nm}$ и мощностью $100 \mathrm{~W}$. Для этого ФПК распределялась между двумя стеклянными пластинами слоем толщиной $100 \mu \mathrm{m}$ и выдерживалась под излучением матрицы светодиодов в течение $5 \mathrm{~min}$. При сравнении такой пленки с образцом пленки, изготовленным на системе двухфотонной фемтосекундной микростереолитографии, установлено, что отличия в спектрах поглощения фотоотвержденных материалов незначительны, как и различие в показателях преломления.

На рис. 2 представлены спектры поглощения образцов ФПК. Определено, что спектр поглощения исходной ФПК после фотоотверждения меняется незначительно. Наблюдается увеличение поглощения вблизи граничной области длин волн $(360 \mathrm{~nm})$, при этом полимерная композиция обладает незначительным поглощением в диапазоне длин волн от $500 \mathrm{~nm}$ и выше. Изменение спектра наиболее вероятно связано с протеканием фотоиндуцированных химических реакций с участием фотоинициатора под действием лазерного излучения. Воздействие высокой температуры (нагрев до $300^{\circ} \mathrm{C}$ ) и термостатирование в течение $1 \mathrm{~h}$ также приводят к незначительному смещению полосы поглощения в длинноволновую область. При последующем нагреве в 
Показатель преломления полимерной композиции

\begin{tabular}{c|c|c}
\hline $\begin{array}{c}\text { Показатель } \\
\text { преломления } \\
\text { неотвержденной } \\
\text { композиции } \\
\text { (рефрактометр) }\end{array}$ & $\begin{array}{c}\text { Показатель } \\
\text { преломления } \\
\text { кеовержденной } \\
\text { композиции } \\
\text { (микроскоп) }\end{array}$ & $\begin{array}{c}\text { Показатель преломления } \\
\text { отвержденной } \\
\text { композиции } \\
\text { (микроскоп) }\end{array}$ \\
\hline $1.53 \pm 0.1$ & $1.53 \pm 0.3$ & $1.52 \pm 0.3$
\end{tabular}

течение нескольких часов изменения спектра не наблюдалось.

Показатель преломления фотоотверждаемой композиции определялся с помощью двух методов. Для исходных жидких образцов ФПК был использован призменный рефрактометр ИРФ-454. Для тонкопленочных образцов измерения показателя преломления проводились с использованием оптического 3D-микроскопа с моторизированным $z$-транслятором и объективом с большим увеличением $(50 \times)$ и малой длиной Релея. Микроскоп позволял замерять точное расстояние между верхней и нижней поверхностями образца, перемещая фокальную плоскость объектива внутри образца с высокой точностью (не хуже $0.1 \mu \mathrm{m}$ ). Используя известную толщину пленки, можно определить точное значение показателя преломления исследуемого образца. Результаты измерения показателя преломления предложенными методами представлены в таблице.

Существенных различий измеренного показателя преломления с помощью двух методов не наблюдается, что позволяет использовать микроскоп для быстрого определения показателя преломления. Также показано, что существенного изменения показателя преломления после процесса фотоотверждения не происходит. Высокий показатель преломления ФПК $(n=1.53)$ позволяет создавать компактные и легкие оптические элементы, что является дополнительным преимуществом в использовании полимерных материалов, что особенно важно при формировании микрооптических компонентов.

\section{Подбор оптимальных параметров печати трехмерных микрообъектов}

Для определения оптимальных параметров процесса лазерного воздействия использовался матричный подход. В ходе экспериментов формировался набор (матрица) одинаковых трехмерных объектов, сформированных при различных параметрах лазерного воздействия и алгоритма сканирования лазерным лучом по объему трехмерной модели (рис. 3). После формирования структуры обдувались воздухом под давлением с целью удаления неотвержденного материала и высушивались при комнатной температуре в течении суток.

В качестве тестовой модели использовалась модель куба размером $200 \times 200 \times 200 \mu \mathrm{m}$ со скругленными гранями с радиусом скругления $10 \mu \mathrm{m}$. Объекты формировались в сплошном слое ФПК толщиной $1 \mathrm{~mm}$.
В экспериментах использовался $20 \times$ объектив с числовой апертурой 0.4 , что позволяло достигать высокой скорости формирования структур (скорость перемещения лазерного луча $25 \mathrm{~mm} / \mathrm{s}$ ). Данный объектив формирует диаметр фокального пятна $\sim 1 \mu \mathrm{m}$.

Для определения диапазона оптимальных параметров было проведено нескольких серий экспериментов. В первой серии экспериментов варьировались такие параметры как скорость сканирования лазерным излучением (от 25 до $75 \mathrm{~mm} / \mathrm{s}$ ) и средняя мощность излучения (от 20 до $80 \mathrm{~mW}$, плотность потока энергии от 0.04 до $\left.0.15 \mathrm{~J} / \mathrm{cm}^{2}\right)$. Было определено, что оптимальные параметры формирования структур при максимальной производительности и сохранении общей формы образцов следующие: скорость движения луча $50 \mathrm{~mm} / \mathrm{s}$ при мощности $60 \mathrm{~mW}$. Во второй серии экспериментов экспериментально определялись параметры заполнения внутреннего объема трехмерной модели - определялось оптимальное расстояние между отдельными слоями (по вертикали), обеспечивающее цельность структуры и плотность заливки отдельного слоя проходами лазерного луча в плоскости $X Y$. Оптимальное расстояние между отдельными слоями составило $2 \mu \mathrm{m}-$ при таком расстоянии удавалось формировать цельную плотную структуру. Это согласуется с длиной Релея для данных условий фокусировки $(\sim 2 \mu \mathrm{m})$.

Наиболее важным параметром, определяющим как время формирования структуры, так и ее плотность, является плотность заливки отдельных слоев, т.е. расстояние между отдельными проходами лазерного излучения. Примеры структур, сформированных с различной плотностью заливки, представлены на рис. $3, a-d$. Было определено, что в случае недостаточного перекрытия при сканировании лазерным излучением (при дистанции между проходами 2 и $3 \mu \mathrm{m}$ ) отвержденные линии не скреплялись между собой, что приводило к формированию несплошной структуры (рис. $3, a, b$ ) с характерным рельефом на боковых поверхностях.

Для получения плотной однородной структуры необходимо было увеличивать перекрытие между линиями и слоями (рис. 3, $c, d$ ), что приводило к увеличению времени формирования структур. Также для получения еще более однородной структуры производилось повышение мощности излучения, что приводило к увеличению области, в которой протекал процесс фотоотверждения ФПК, что позволяло формировать сплошной объем фотоотвержденного материала (рис. 3,c) без использования максимальной плотности заливки (рис. 3,d). Однако стоит отметить, что избыточное увеличение мощности лазерного излучения и перекрытия между отдельными проходами лазерного излучения могло приводить к небольшой деформации конечной формы сформированной структуры (рис. $3, d)$.

В результате экспериментов были определены оптимальные параметры отверждения ФПК, которые составили: скорость сканирования - $50 \mathrm{~mm} / \mathrm{s}$, мощность излучения - $60 \mathrm{~mW}$, расстояние между слоями - 

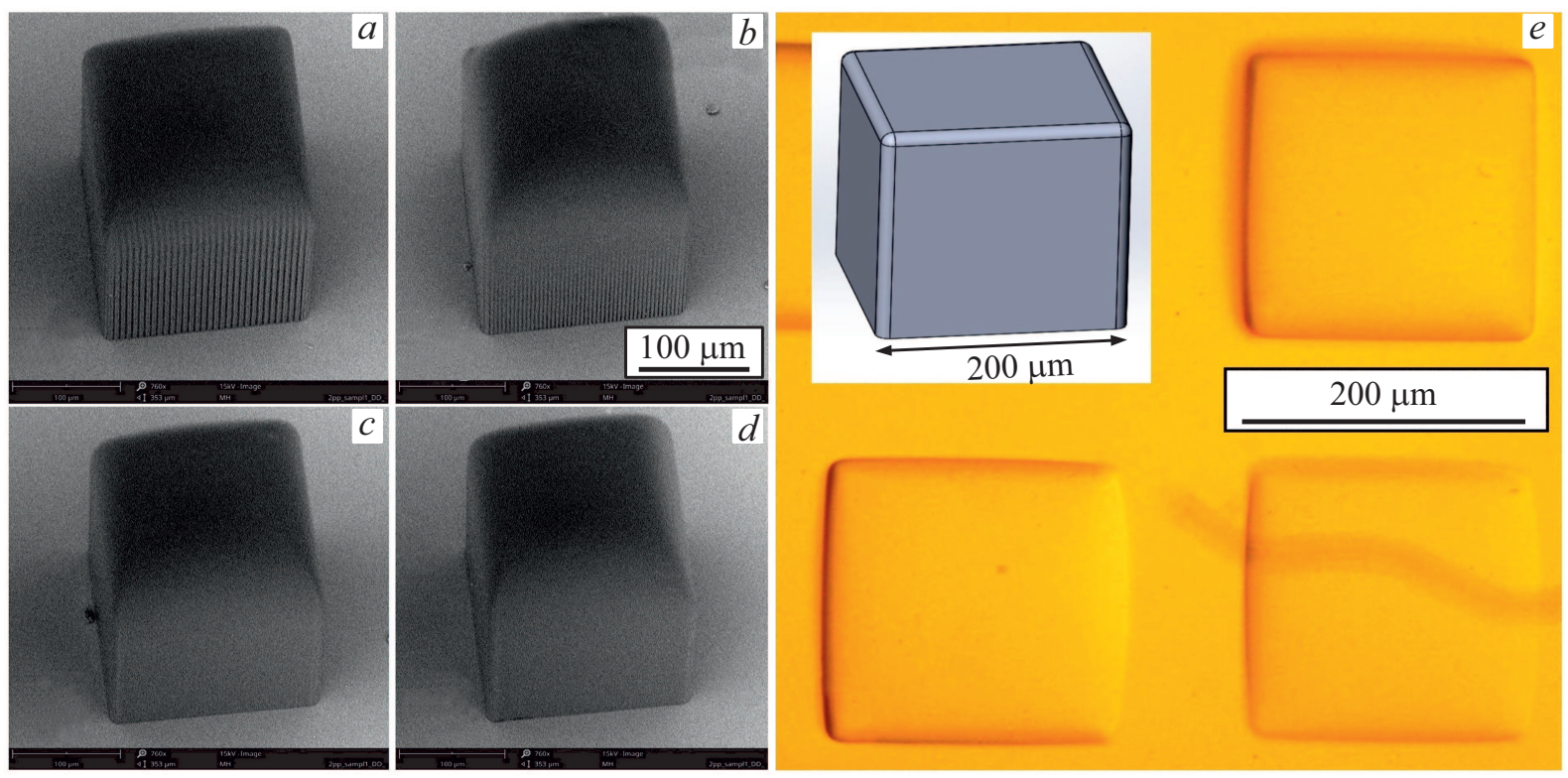

Рис. 3. Фотографии отдельной серии тестовых трехмерных структур. Слева - электронные фотографии структур, напечатанных при различном расстоянии между отдельными линиями $(a-3 \mu \mathrm{m}, b-2 \mu \mathrm{m}, c-1 \mu \mathrm{m}, d-0.5 \mu \mathrm{m})$. Справа $(e)-$ фотографии сформированных структур с оптимальными параметрами, снятые оптическим микроскопом; в верхнем левом углу - формируемая трехмерная модель.

$2 \mu \mathrm{m}$, расстояние между соседними линиями $-1 \mu \mathrm{m}$. На рис. 3,e приведены оптические фотографии изготовленных структур с использованием оптимальных параметров для исследования воспроизводимости. Изготовленные структуры были прозрачны, однородны, стойки к механическим воздействиям (процесса очистки от неотвержденного полимера, манипуляции пинцетом).

Разрешение печати было экспериментально определено с помощью электронного микроскопа при формировании одиночной линии при мощности излучения $60 \mathrm{~mW}$ и составило менее $2 \mu \mathrm{m}$ в плоскости $X Y$ для объектива с увеличением $20 \times$ и числовой апертурой 0.4 .

\section{Заключение}

В ходе проведенной работы были исследованы оптические свойства оригинальной ФПК на основе термостойкого ароматического полиамида, а также их изменение после процесса фотоотверждения и воздействия высоких температур. Подобраны оптимальные параметры формирования трехмерных микроструктур методом двухфотонной фемтосекундной полимеризации, обеспечивающие разрешение печати не хуже $2 \mu \mathrm{m}$ и повторяемость результата. Сохранение оптических свойств ФПК при воздействии температур до $300^{\circ} \mathrm{C}$ и высокая прозрачность в широком диапазоне длин волн показывают перспективность использования разработанной ФПК для формирования термостойких микрооптических элементов сложной асферической формы, не имеющей симметрии, по заданной компьютерной трехмерной модели.
Разработанная ФПК в сочетании с технологией двухфотонной фемтосекундной микростереолитографии может быть использована для широкого круга применений, например для создания волоконных каплеров [34], фотонных кристаллов [35], микролинзовых растров [36,37], линз и пластин Френеля [38]. Стоит отметить, что результат особо интересен с точки зрения быстрого формирования смоделированных на компьютере микрооптических систем, а также для коллимации и фокусировки излучения мощных лазерных систем и диодных лазеров, работающих при повышенных температурах.

\section{Финансирование работы}

Работа выполнена при финансовой поддержке РФФИ (№ 18-32-00414 в части двухфотонной микростереолитографии и 18-07-01052 в части разработки новых фотоотверждаемых материалов), а также Министерства науки и высшего образования в рамках исполнения работ по Государственным заданиям ФНИЦ „Кристаллография и фотоника“" РАН (в части развития аддитивных лазерных технологий) и Байкальского института природопользования СО РАН (в части получения полимерной композиции).

\section{Конфликт интересов}

Авторский коллектив заявляет об отсутствии конфликта интересов. 


\section{Список литературы}

[1] Bahk S.W., Fess E., Kruschwitz B.E., Zuegel J.D. // Optics Express. 2010. V. 18. N 9. P. 9151-9163.

[2] Garmire E. PatentUSA 8666207, 2014.

[3] Ghasemi S.H., Hantehzadeh M., Sabbaghzadeh J., Dorranian D., Lafooti M., Vatani V., Rezaei-Nasirabad R., Hemmati A., Amidian A.A., Alavian S.A. // Applied Optics. 2011. V. 50. N 18. P. 2927-2930.

[4] Malinauskas M., Žukauskas A., Purlys V., Belazaras K., Momot A., Paipulas D., Gadonas R., Piskarskas A., Gilbergs H., Gaidukevičiūtè A., Sakellari I., Farsari M. Juodkazis S. // J. Optics. 2010. V. 12. N 12. P. 124010.

[5] Yuan S., Yang H., Xie K. // Optik. International J. Light and Electron Optics. 2010. V. 121. N 18. P. 1708-1711.

[6] Chen X., Lin J., Liu Z., Wu P., Wang H. // Optical Review. 2017. V. 24. N 1. P. $62-71$.

[7] Willis K., Brockmeyer E., Hudson S., Poupyrev I. // Proceedings 25th Annual ACM Symposium on User Interface Software and Technology. 2012. P. 589-598.

[8] Chen X., Liu W., Dong B., Lee J., Ware H.O.T., Zhang H.F., Sun C. // Advanced Materials. 2018. V. 30. N 18. P. 1705683.

[9] Thiele S., Gissibl T., Giessen H., Herkommer A.M. // Optics Letters. 2016. V. 41. N 13. P. 3029-3032.

[10] Guo R., Xiao S., Zhai X., Li J., Xia A., Huang W. // Optics Express. 2006. V. 14. N 2. P. 810-816.

[11] Jonušauskas L., Gailevičius D., Mikoliūnaité L., Sakalauskas D., Šakirzanovas S., Juodkazis S., Malinauskas M. // Materials. 2017. V. 10. N 1. P. 12.

[12] Kotz F., Arnold K., Bauer W., Schild D., Keller N., Sachsenheimer K., Nargang T.M., Richter C., Helmer D., Rapp B.E. // Nature. 2017. V. 544. N 7650. P. 337-339.

[13] Sultanova N.G., Kasarova S.N., Nikolov I.D. // Optical and Quantum Electronics. 2013. V. 45. N 3. P. 221-232.

[14] Kholkhoev B.C., Bardakova K.N., Minaev N.V., Kupriyanova O.S., Gorenskaia E.N., Zharikova T.M., Tima-shev P., Burdukovskii V.F. // Mendeleev Commun. 2019. V. 29. N 2. P. 223-225.

[15] Dudova D.S., Bardakova K.N., Kholkhoev B.C., Ochirov B.D., Gorenskaia E.N., Farion I.A., Burdukovskii V.F., Timashev P., Minaev N., Kupriyanova O.S. // J. Applied Polymer Science. 2018. V. 135. N 27. P. 46463.

[16] Saha S.K., Wang D., Nguyen V.H., Chang Y., Oakdale J.S., Chen S.C. // Science. 2019. V. 366. N 6461. P. 105-109.

[17] Hahn V., Kiefer P., Frenzel T., Qu J., Blasco E., BarnerKowollik C., Wegener M. // Adv. Funct. Mater. 2020. V. 1907795. P. 1907795.

[18] Chu W., Tan Y., Wang P., Xu J., Li W., Qi J., Cheng Y. // Advanced Materials Technologies. 2018. V. 3. N 5. P. 1700396.

[19] Farsari M., Chichkov B.N. // Nature Photonics. 2009. V. 3. N 8. P. 450.

[20] Seet K.K., Juodkazis S., Jarutis V., Misawa H. // Applied Physics Letters. 2006. V. 89. N 2. P. 024106.

[21] Serbin J., Egbert A., Ostendorf A., Chichkov B.N., Houbertz R., Domann G., Schulz J., Cronauer C., Fröhlich L., Popall M. // Optics Letters. 2003. V. 28. N 5. P. 301-303.

[22] Bhuian B., Winfield R.J., O'Brien S., Crean G.M. // Applied Surface Science. 2006. V. 252. N 13. P. 4845-4849.

[23] Farsari M., Vamvakaki M., Chichkov B.N. // J. Optics. 2010. V. 12. N 12. P. 124001.
[24] Ovsianikov A., Viertl J., Chichkov B., Oubaha M., MacCraith B., Sakellari I., Giakoumaki A., Gray D., Vamvakaki M., Farsari M., Fotakis C. // AcsNano. 2008. V. 2. N 11. P. 2257-2262.

[25] Schizas C., Melissinaki V., Gaidukeviciute A., Reinhardt C., Ohrt C., Dedoussis V., Chichkov B., Fotakis C., Farsari M., Karalekas D. // Intern. J. Advanced Manufacturing Technology. 2010. V. 48. N 5. P. 435-441.

[26] Qiu W., Hu P., Zhu J., Liu R., Li Z., Hu Z., Chen Q., Dietliker K., Liska R. // ChemPhotoChem. 2019. V. 3. N 11. P. 1090-1094.

[27] Wilhelm V., Hellmann G.P. // Polymer. 2000. V. 41. P. 1905-1915.

[28] Burdukovsky V., Kholkhoev B., Farion I., Timashev P., Pudovkina G. // Phononics. 2016. V. 2. P. 46-63

[29] Gissibl T., Thiele S., Herkommer A., Giessen H. // Nature Photonics. 2016. V. 10. N 8. P. 554.

[30] Baldacchini T. William Andrew. 2015. P. 486.

[31] Hegde M., Meenakshisundaram V., Chartrain N., Sekhar S., Tafti D., Williams C.B., Long T.E. // Adv. Mater. 2017. V. 29. N 31. P. 1-7.

[32] Demina T.S., Bardakova K.N., Minaev N.V., Svidchenko E.A., Istomin A.V., Goncharuk G.P., Vladimirov L.V., Grachev A.V., Zelenetskii A.N., Timashev P., Akopova T.A. // Polymers. 2017. V. 9. N 7. P. 302.

[33] Shavkuta B.S., Gerasimov M.Y., Minaev N.V., Kuznetsova D.S., Dudenkova V.V., Mushkova I.A., Malyugin B.E., Kotova S.L., Timashev P.S., Kostenev S.V., Chichkov B.N., Bagratashvili V.N. // Laser Physics Letters. 2017. V. 15. N 1. P. 015602.

[34] Lindenmann N., Balthasar G., Hillerkuss D., Schmogrow R., Jordan M., Leuthold J., Freude W., Koos C. // Opt. Express. 2012. V. 20. N 16. P. $17667-17677$.

[35] Tian Y., Kwon H., Shin Y.C., King G.B. // J. Micro and NanoManufacturing. 2014. V. 2. N 3. P. 1.

[36] Yang L., El-Tamer A., Hinze U., Li J., Hu Y., Huang W., Chu J., Chichkov B.N. // Optics and Lasers in Engineering. 2015. V. 70. P. 26-32.

[37] Hu Y., Chen Y., Ma J., Li J., Huang W., Chu J. // Applied Physics Letters. 2013. V. 103. N 14. P. 141112.

[38] Zhang C., Hu Y., Li J., Li G., Chu J., Huang W. // Optics Express. 2014. V. 22. N 4. P. 3983-3990. 